\title{
THE WAYS OF EMPHASIZING THE INTENSITY OF EMOTIONAL EXPERIENCE IN THE HAGIOGRAPHIC TEXTS OF THE SYNODAL PERIOD ${ }^{1}$
}

\author{
Evgeniya G. Dmitrieva \\ Volgograd State University, Volgograd, Russia
}

\begin{abstract}
The paper provides the analysis of emotive vocabulary usage in the hagiographic texts of the synodal period: The Life of Dimitry of Rostov, The Life of Hilarion of Suzdal, The Life of Mitrophan of Voronezh, and The Life of Tikhon of Zadonsk. The factual language material has been analyzed with respect to the complex approach to the language in use, i.e. intralinguistic analysis of language unit structures, paradigmatic and syntagmatic relations at various levels of the language hierarchy, and their functional realizations in the contexts under study.

The markers of one of the most important characteristics of emotional experience - its intensity -include the use of lexical units expressing the emotions of high intensity in direct or figurative meaning, as well as non-emotive verbs with semantics of unusually active action or its abrupt termination to denote the emotional experience of the subject of action; use of words denoting opposite positive and negative emotional experiences or their manifestations in the same context; contextual specifiers of measure and degree; indication of emotional experience's duration, emotional impact's speed, the universality of feelings' manifestations; tautological repetitions; gradation method.

Comparison of the obtained results with the results of analysis of ancient Russian and old Russian texts makes it possible to identify the dynamics of methods of expressing the feelings of high intensity.

Key words: history of the Russian language, hagiographic text, lexis, emotive lexical units, intensity, characterological function.

Citation. Dmitrieva E.G. The Ways of Emphasizing the Intensity of Emotional Experience in the Hagiographic Texts of the Synodal Period. Vestnik Volgogradskogo gosudarstvennogo universiteta. Seriya 2, Yazykoznanie [Science Journal of Volgograd State University. Linguistics], 2018, vol. 17, no. 1, pp. 44-51. (in Russian). DOI: https://doi.org/10.15688/jvolsu2.2018.1.5
\end{abstract}

\section{СПОСОБЫ УКАЗАНИЯ НА ИНТЕНСИВНОСТЬ ЭМОЦИОНАЛЬНОГО ПЕРЕЖИВАНИЯ В ЖИТИЙНЫХ ТЕКСТАХ СИНОДАЛЬНОГО ПЕРИОДА ${ }^{1}$}

\section{Евгения Геннадьевна Дмитриева}

Аннотация. В статье рассматриваются особенности использования лексики эмоций в агиографических памятниках синодального периода: Житии Димитрия Ростовского, Житии Илариона Суздальского, Житии Митрофана Воронежского и Житии Тихона Задонского. Анализ языковых фактов проводился с позиций комплексного подхода, предполагающего рассмотрение внутренней системной организации языковых единиц, парадигматических и синтагматических отношений на различных языковых уровнях, а также с учетом особенностей функционирования единиц в контексте. 
Выявлены способы передачи одной из важнейших характеристик эмоционального переживания - его интенсивности: употребление лексических единиц, в прямом или переносном значении называющих эмоции высокой степени интенсивности, а также неэмотивных глаголов с семантикой необычно активного действия или его резкого прекращения для обозначения эмоционального переживания субъекта действия; использование в одном контексте лексем, обозначающих противоположные положительные и отрицательные эмоциональные переживания или их проявления; контекстуальные уточнители меры и степени; указание на длительность эмоционального переживания, на скорость эмоционального воздействия, на всеобщий характер проявления чувства; тавтологические повторы; прием градация.

Сопоставление полученных результатов с результатами анализа древнерусских и старорусских текстов позволило выявить динамику приемов передачи чувств высокой интенсивности.

Ключевые слова: история русского языка, житийный текст, лексика, лексика эмоций, интенсивность, характерологическая функция.

Цитирование. Дмитриева Е. Г. Способы указания на интенсивность эмоционального переживания в житийных текстах синодального периода // Вестник Волгоградского государственного университета. Серия 2 , Языкознание. -2018. - Т. 17, № 1. - C. 44-51. - DOI: https://doi.org/10.15688/jvolsu2.2018.1.5

\section{Интенсивность эмоций в психологии и лингвистике}

Выявляя особенности описания людей в житийной литературе конца XIV - XV в., Д.С. Лихачев отмечал, что изображение «психологической жизни» предшествовало открытию характера. Психологические состояния в текстах этого времени «могут меняться с необычайной быстротой, достигать невероятных размеров» [Лихачев, 1956, с. 106]. В этой связи исследование эволюции способов указания на силу эмоционального переживания в древнерусских, старорусских и синодальных житийных текстах приобретает несомненный интерес.

Психологи констатируют, что «чувствам, как и ощущениям, присущи свойства качества и интенсивности» [Вилюнас, 1990, с. 207]. В работах исследователей представлены различные классификации эмоциональных состояний, однако в большинстве источников выделяются особые виды эмоциональных процессов: аффект - стремительно и бурно протекающий эмоциональный процесс взрывного характера, и страсть сильное, стойкое, длительное чувство. Общим для них является «количественный момент интенсивности эмоционального возбуждения» [Рубинштейн, 1999, с. 580]. Таким образом, «если удивление мы называем чувством, то изумление - то же самое по содержанию чувство, доведенное до степени аффекта...; обожание - это любовь, по силе и продолжительности ставшая страстью» [Лук, 1982, с. 30].
Если принять точку зрения, поддерживаемую большинством психологов, согласно которой чувства являются высшими, социальными, а эмоции - низшими, биологическими формами эмоциональных состояний (эмоциональных процессов, эмоций), то, как представляется, различия в глубине эмоций можно сопоставить с различиями эмоций и чувств, тогда как интенсивность будет отличать эмоции и чувства от аффекта и страсти.

В православной традиции количественные различия в силе эмоционального переживания (интенсивность) переосмысляются как качественные и получают соответствующую морально-нравственную оценку. Так, святитель Феофан Затворник писал: «Всякая страсть есть тяжкий и смертный грех, ибо отдаляет от Бога и погашает ревность к богоугодной жизни» [Святитель Феофан Затворник, 2004, с. 12].

В лингвистике интенсификацию признака связывают с реализацией особой семантической категории - интенсивности, исследование которой в отечественном языкознании имеет достаточно длительную традицию (см. об этом: [Бельская, 2004]). Тем не менее ее сущность, статус и место среди других языковых категорий продолжают оставаться предметом научной дискуссии [Родионова, 2004, с. 300-301]. В частности, дискуссионным остается вопрос об объективности / субъективности оценивания интенсивности применительно к силе эмоционального переживания.

Для носителя языка, по мнению Ю.Д. Апресяна, «эмоции отличаются друг от друга по 
признакам интенсивности и глубины переживания», причем русскую языковую картину мира характеризуют наличие лексем, описывающих «норму интенсивности» и «бо́льшую степень интенсивности», и практически отсутствие антонимически противопоставленных лексем со значением «слабых эмоций» [Апресян, 1995, с. 371].

Языковеды, подчеркивая субъективный характер категории интенсивности, связывают ее с реализацией в семантике языковой единицы компонента 'очень', отражающего представления об отклонении от привычного для говорящего порядка вещей.

\section{Интенсивность}

\section{эмоционального переживания}

как семантический компонент лексического значения

Ранее проведенный нами анализ употребления эмотивных глаголов в древнерусских и старорусских житийных текстах показал, что положительная / нейтральная / отрицательная оценка обозначаемой глаголом эмоции, ее интенсивность (наряду со статусом описываемого субъекта и причиной эмоционального переживания) являются важнейшими факторами, определяющими специфику реализации эмотивным глаголом характерологической функции [Дмитриева, 2011].

Повышенная экспрессивность в выражении эмоциональных переживаний потребовала ее учета и при реконструкции семантической структуры древнерусских и старорусских глаголов эмоций [Семантика древнерусского глагола..., 2015, с. 180-240]. Выявляя релевантные признаки в семантике эмотивных глаголов, мы связали силу эмоциональногопереживания, силу проявления эмоций и чувств с интегральной семой 'степень интенсивности эмоционального переживания', которая может быть реализована в дифференциальных признаках «высокая», «средняя», «низкая». Перечисленные компоненты также обнаруживаются в семантической структуре существительных, прилагательных и наречий, обозначающих психические процессы и состояния (см., например: [Дмитриева, 2017]).

В определении степени интенсивности эмоционального переживания, обозначаемого той или иной лексемой, мы опирались прежде всего на данные исторических и толковых словарей, позволяющие выстроить синонимические ряды с учетом этого семантического признака, а также на анализ контекста. О низкой степени интенсивности дают возможность судить словарные материалы. В нашей картотеке такие случаи единичны: в частности, глагол прослезиться в синонимическом ряду прослезиться - плакать - рыдать может быть определен как глагол, обозначающий низкую степень интенсивности. О высокой степени интенсивности переживания свидетельствуют лексикографические данные или контекстуальные уточнители. В случае, когда на высокую или низкую интенсивность эмоционального переживания не указывают ни словарные дефиниции, ни контекст, мы относим такие лексемы к обозначающим переживание средней степени интенсивности.

\section{Способы указания на интенсивность эмоций в житийном тексте}

Ранее было установлено, что в житийных текстах древнерусского и старорусского периодов основными способами передачи интенсивности эмоционального переживания являются: употребление эмотива в прямом или переносном значении; использование неэмотивных глаголов с семантикой необычно активного действия или его резкого прекращения для обозначения эмоционального переживания субъекта действия; контекстуальные уточнители меры и степени; прием градации; тавтологические повторы; антонимы; синонимы, один из которых предполагает обозначение внутреннего переживания, а второй - его внешнее проявление; указание на количественные характеристики, выраженные счетным словом или местоимением.

Объектом для данного исследования послужила лексика эмоций, функционирующая в оригинальных агиографических памятниках синодального периода - Житии Димитрия Ростовского, Житии Илариона Суздальского, Житии Митрофана Воронежского и Житии Тихона Задонского.

В названных текстах были выявлены некоторые особенности употребления эмотивов, дающие представление о способах пере- 
дачи степени интенсивности эмоционального переживания.

1. Употребление лексических единиц, в прямом или переносном значении называющих эмоции высокой степени интенсивности.

Семантика высокой степени интенсивности эмоционального переживания может содержаться в прямом или переносном значении самой лексемы. Так, в семантической структуре существительного ненависть «враждебное расположение, зложелательство»; «отвращение» (СЦСиРЯ, т. II, с. 440) реализуется дифференциальный признак 'состояние эмоционального переживания', состояние принадлежит к сфере субъекта, а переживание является отрицательным чувством, характеризуется высокой степенью интенсивности и направлено на одушевленный объект. В житийном фрагменте: Одинъ изъ братіи, уличенный Иларіономь въ утайк' незначительной суммы братскихъ денегъ, воспьлаль такою ненавистью къ игумену, что р жиился убить его топоромь (ЖСИ, с. 1314), - существительное ненавистью реализует приведенное выше прямое значение, о чем свидетельствуют одушевленный, конкретный объект къ игумену, а также сочетание одинъ изъ братіи, указывающее на конкретный, одушевленный субъект.

В семантической структуре глагола гневаться «предаваться гневу, сердиться» (СЦСиРЯ, т. I, с. 269) актуализируется дифференциальный признак 'процесс эмоционального переживания’, процесс является состоянием-отношением, принадлежащим к сфере субъекта, а переживание - отрицательным чувством, характеризующимся высокой степенью интенсивности и направленным на одушевленный объект. В житийном фрагменте: Иларіонъ не только не гн ъвался на него, но даже ухаживаль за нимь за больнымь, и когда тоть умеръ, то самъ отп қль его, похорониль своими руками, оплакавъ гр $\mathbf{k} x и$ его (ЖСИ, с. 14), - глагол гн ввался используется в прямом значении.

К традиционным приемам создания образности в житийной литературе можно отнести уподобление чувств человека огню, потоку влаги. Метафоры «чувство - огонь», «эмоции поток» позволяют охарактеризовать сильные эмоциональные переживания.
Так, в результате семантического развития основного значения глагол изливать «лить из чего-либо» (СЦСиРЯ, т. II, с. 114) мог получать значение, не отмеченное в словаре: $\mathrm{He}$ токмо въ блаженные дни благочестивыхъ нашихъ предковъ, духомь по православію гор ъвшихъ, умножаль Господь чудеса Свои, явленіемъ изъ-подь спуда персти земной св ътильниковъ Своея благодати, во

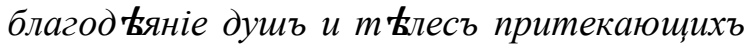
къ нимъ съ в 'рою; праведный любяй, гр финыя милуяй, и въ наши скудныя в фрою времена изліяль на насъ обильную струю той жее неизреченной Своей милости, да напоить изсыхающія малов фріемь сердияа наши къ прозябенію въ нихъ христіанской доброд фтели, яко въ нареченныхъ чадахъ Своихъ по в (ЖМВ, с. 4). На реализацию эмотивной семантики в житийном контексте указывает употребление абстрактного существительного милости со значением «расположение, готовность оказывать благодеяние, снисхождение, пощаду» (СЦСиРЯ, т. II, с. 304); об интенсивности характеризуемого им эмоционального отношения свидетельствует также прилагательное обильную, зафиксированное в словаре со значением «богатый, избыточный» (СЦСиРЯ, т. III, с. 13).

В результате семантического развития основного значения глагол восnылать мог получать значение: «начать пылать» $\rightarrow$ «возчувствовать действие сильной страсти» (СЦСиРЯ, т. I, с. 165), ср.: Одинъ изъ братіи, уличенный Иларіономь въ утайк' незначительной суммы братскихъ денегъ, воспьлаль такою ненавистью къ игумену, что рқиился убить его топоромь (ЖСИ, с. 13-14). О реализации эмотивного значения в житийном контексте свидетельствует употребление словоформы ненавистью, на интенсивность эмоционального переживания также указывает последующее действие - $p$ tиился убить его топоромъ.

2. Употребление контекстуальных уточнителей меры и степени. В их качестве, как правило, выступают наречия и прилагательные, сочетающиеся с субстантивными наименованиями эмоций: Царь Єеодорь сильно возжелаль увид қть пустынника... (ЖСИ, с. 21); Пустынникъ сильно быль смущенъ... 
(ЖСИ, с. 21); ...но прежде всего и больше всего любиль онъ Господа и внимательно изучаль пути Его (ЖТЗ, с. 9); а онъ чувствуетъ только одну духовную радость, которая сжимаеть его сердие и заставляеть его источать обильныя слезы (ЖСИ, с. 18); Съ большимъ смущеніемъ предстали они къ своему владык ' (ЖТЗ, с. 11).

3. Указание на длительность эмоционального переживания, его бесконечность, посредством наречий времени, а также имен существительных и прилагательных: Такимъ образомъ едва не съ младенчества Богу угодно было поставить Іоанна свид қтелемь суровыхъ иноческихъ подвиговъ - $u$ зд $\mathbf{k} c b$, въ безмолвіи монастыря, въ пост $\mathbf{k}$, молитв $\mathbf{k}$, послушаніи, хожденіи въ иеерковь,

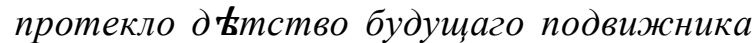

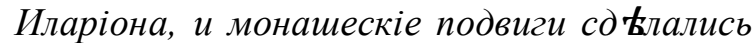
навсегда любимымъ занятіемъ отрока Іоанна (ЖСИ, с. 4); Бес ъда его, шедшая оть сердиа и растворенная благодатію, такъ восхитила иаря, что онъ навсегда полюбиль подвижника благочестія... (ЖСИ, с. 21); Съ такой любовію, съ такимъ отеческимь вниманіемъ св. Димитрій относился къ питомиамъ своей школь до конца жизни (ЖДР, с. 21); Эти тяжелье годы своего печальнаго д $\mathbf{k}$ ства св. Тихонь вспоминаль не безъ грусти, даже будучи уже въ преклонныхъ л қтахъ (ЖТЗ, с. 6). Важно, что подобным постоянством характеризуются обычно положительные эмоции. В этой связи последний пример является своего рода исключением, поскольку связан с переживанием отрицательного чувства - грусти.

4. Указание на скорость эмоционального воздействия. Контексты, в которых обнаруживается такое указание, немногочисленны и связаны с использованием наречий: Пустынножители съ радостію приняли Іоанна, а праведный подвижникъ, старецъ Меөодій, скоро полюбиль пришельиа за его начитанность въ Св. писаніи и предрекъ, что Іоаннь со временемь устроить зд tсь обитель, которая будеть впосл $\mathbf{b}$ ствіи знаменитой (ЖСИ, с. 6-7).

5. Указание на всеобщий характер проявления чувства. Для этого в тексе используются формы местоимения весь: Словомъ, онъ быль такимъ пастыремъ добрымъ и мило- стивымъ, что вс ' въ епархіи полюбили его, какъ истиннаго отиа (ЖСИ, с. 25); Умный, кроткій и услужливый юноша Іоаннъ скоро сд ълался любимиемь всей семьи въ с. Кириков ъ... (ЖСИ, с. 5).

6. Употребление неэмотивных глаголов с семантикой необычно активного действия или его резкого прекращения для обозначения эмоционального переживания субъекта действия. Например: Повергнемся въ прахъ предь милующимъ нась Богомъ и припадемъ ко Господу благод кющему намъ, и въ восторг $\mathbf{k}$ духовныя нашея радости хвалу Ему принося о новомъ и щедромъ Его дар $\mathbf{k}$ воскликнемъ сердцемъ и устами: не сотвори тако всякому языку, и судьбы Своя, судьбы отеческія Своея благости къ избраннымь людямъ Святымъ не яви имъ (ЖМВ, c. 4-5). В приведенных контекстах глаголы повергнемся и воскликнемъ выполняют характерологическую функцию, описывая внешниепроявления эмоционального переживания.

7. Тавтологические повторы однокоренных слов. Например: ...монашескіе подвиги сд Ћлались навсегда любимымъ занятіемъ отрока Іоанна. ....зд $\mathbf{k} c$ в въ монастыр $\mathbf{t} \mathrm{cb}$ любовію предавался чтенію св. писанія и душеполезныхъ книгъ. ...и инокъ Антоній думаль, что любимый сынъ его останется навсегда въ монастыр ъ (ЖСИ, с. 4), а также использование синонимов: Отn $\mathbf{k}$ ваніе его, при многочисленномь стеченіи плакавщаго $и$ рыдавщаго народа, произошло 30-го декабря (ЖСИ, с. 27). Значимым является выбор повторяющихся слов: в подавляющем большинстве случаев это лексемы с корнем -люб-.

8. Употребление в одном контексте лексем, обозначающих противоположные положительные и отрицательные эмоциональные переживания или их проявления. Таким образом передаются сильные эмоции и чувства: Трогательна была встр ъча юнаго инока съ пустынножителями. Обливаясь слезами, встр ттили иноки Иларіона, радуясь, что Богъ привель его исполнить давнишнее об ъщаніе (ЖСИ, с. 8). В приведенном контексте агиограф в качестве уточнения образа действия использует словоформы обливаясь (слезами) и радуясь, которые указывают на проявление противоположных в бытовом представлении чувств. Радость и слезы - это 
столкновение проявлений удовольствия и неудовольствия (положительной и отрицательной эмоций). Это позволяет говорить о том, что в подобных контекстах, совмещающих полярные эмоции, посредством контраста передается не только высокая интенсивность переживаемых чувств, но и сложность внутреннего состояния человека.

9. Прием градации. В житийном тексте для передачи динамики эмоционального переживания используются ряды эмотивных лексем, организованных по принципу нарастания интенсивности эмоционального переживания: Егда же сей преподобный начнетъ акаӨисть Пресвят Һй Богородии' читати, абіе бысть въ то время оть него н ъкоторый дивный, страшный и умилительный гласъ, оть его исходящій... громогласенъ $и$ сладкоглаголивъ и медоточенъ... (ЖСИ, c. 18). Агиограф создает разворачивающуюся перед глазами читателя картину нарастающего эмоционального воздействия.

\section{Выводы}

Таким образом, анализ функционирования эмотивных лексем в житийных текстах синодального периода показал, что интенсивность выступает значимой характеристикой эмоционального переживания. Особенно важна высокая степень проявления данного признака, для передачи которой агиографическая традиция использует разнообразные конструкции и приемы.

Так, на материале текстов святительских житий рубежа XIX-XX вв. удалось выявить приемы, посредством которых реализуются парадигматические и синтагматические свойства лексических единиц.

Сопоставление с наблюдениями, сделанными на материале древнерусских и старорусских житий, показывает, что основной состав контекстуальных способов указания на интенсивность эмоционального переживания сохраняется, однако если в ранних текстах значительно преобладают такие контекстуальные приемы, как использование уточнителей меры и степени, а также тавтологические повторы, то в агиографических текстах синодального периода автор стремится разнообразить средства выражения интенсивно- сти, указывая на длительность эмоционального переживания, включенность в него большого количества людей, скорость эмоционального воздействия.

\section{ПРИМЕЧАНИЕ}

${ }^{1}$ Исследование выполнено при финансовой поддержке РФФИ, проект № 17-34-01009 (а2) «Отражение представлений о нравственном идеале в языке русской оригинальной агиографии XVIII$\mathrm{XX}$ веков».

\section{СПИСОК ЛИТЕРАТУРЫ}

Апресян Ю. Д., 1995. Образ человека по данным языка: попытка системного описания // Избранные труды : в 2 т. Т. II. Интегральное описание языка и системная лексикография. М. : Школа «Языки русской культуры». С. 348-388.

Бельская Е. В., 2004. Проблема интенсивности в современной отечественной лексикологии // Beстник Томского государственного университета. № 282. С. 202-210.

Вилюнас В. К., 1990. Психологические механизмы мотивации человека. М. : Изд-во МГУ. 288 с.

Дмитриева Е. Г., 2011. Характерологическая функция эмотивной глагольной лексики в древнерусских и старорусских текстах // Слово в языке и тексте : сб. ст. к 85-летию со дня рождения Софии Петровны Лопушанской. Волгоград : Волгогр. науч. изд-во. С. 42-55.

Дмитриева Е. Г., 2017. Об эмоциональном и рациональном в тексте «Русской Правды» // Вестник Волгоградского государственного университета. Серия 2, Языкознание. Т. 16, № 1. C. 35-46. DOI: https://doi.org/10.15688/jvolsu2. 2017.1.3.

Лихачев Д. С., 1956. Изображение людей в житийной литературе конца XIV - XV века // Труды отдела древнерусской литературы. М. : АН CCCP. T. XII. C. 105-115.

Лук А. Н., 1982. Эмоции и личность. М. : Знание. 176 с.

Родионова С. Е., 2004. Интенсивность и ее место в ряду других семантических категорий // Славянский вестник. М. : МАКС Пресс. Вып. 2. C. 300-313.

Рубинштейн С. Л., 1999. Основы общей психологии. СПб. : Питер Ком. 720 с.

Святитель Феофан Затворник, 2004. Страсти и борьба с ними: выдержки из творений и писем. М. : Даниловский благовестник. 326 с.

Семантика древнерусского глагола..., 2015. Семантика древнерусского глагола: синхронно-ди- 
ахронический аспект : коллектив. моногр. / О. А. Горбань, Е. Г. Дмитриева, М. В. Косова [и др.]; отв. ред. Е. М. Шептухина. 2-е изд., доп. М. : Флинта : Наука. 352 с.

\section{ИСТОЧНИКИ И СЛОВАРИ}

ЖДР - Житие святого Димитрия, митрополита Ростовского. Ростов-Ярославский : Типография А.Х. Оппель, на Окружной улице, 1902. 32 с.

ЖMB - Житие иже во святых отца нашего Митрофана, в схимонасех Макария, первого епископа Воронежского и новоявленного чудотворца и Сказание о обретении и открытии честных его мощей, и о благодатных при том знамениях и чудесных исцелениях : Извлеч. из актов и донесений, имеющихся в Святейшем Синоде. 13-е изд. Москва : Синод. тип., $1896.74 \mathrm{c}$.

ЖСИ-Георгиевский В. Т. Житие и подвиги святителя Илариона, митрополита Суздальского ([ум.] 1707 г.). Петроград : М.Д. Усов, 1914. 28 с.

ЖТЗ - Житие святителя Тихона, епископа Воронежского, Задонского и всея России чудотворца. Одесса : Тип. и хромолит. Е.И. Фесенко, 1895. $36 \mathrm{c}$.

СЦСиРЯ - Словарь церковно-славянскаго и русскаго языка, составленный Вторымъ отдтленіемъ Императорской Академіи наукъ : в 4 т. СанктПетербургъ : Въ Типографіи Императорской Академіи наукъ, 1847.

\section{REFERENCES}

Apresyan Yu.D., 1995. Image of the person according to language: attempt of the system description. Izbrannye trudy: $v 2 t$. T. II. Integralnoe opisanie yazyka i sistemnaya leksikografiya. Moscow, Yazyki russkoy kultury Publ., pp. 348-388.

Belskaya E.V., 2004. The problem of intensity in modern domestic lexicology. Vestnik Tomskogo gosudarstvennogo universiteta [Tomsk State University Journal], no. 282, pp. 202-210.

Vilyunas V.K., 1990. Psychological mechanisms of human motivation. Moscow, Izd-vo MGU. $288 \mathrm{p}$.

Dmitrieva E.G., 2011. Characterological function of the emotional verbal lexicon in ancient Russian and old Russian texts. Slovo v yazyke i tekste: sb. st. k 85-letiyu so dnya rozhdeniya Sofii Petrovny
Lopushanskoy. Volgograd, Volgogradskoe nauchnoe izd-vo, pp. 42-55.

Dmitrieva E.G., 2017. On the emotional and the rational in the text of the Russkaya Pravda. Vestnik Volgogradskogo gosudarstvennogo universiteta. Seriya 2, Yazykoznanie [Science Journal of Volgograd State University. Linguistics], 2017, vol. 16, no. 1, pp. 35-46. DOI: https://doi.org/ 10.15688/jvolsu2.2017.1.3.

Likhachev D.S., 1956. The image of people in the hagiographic literature of the late $14^{\text {th }}-15^{\text {th }}$ century. Trudy otdela drevnerusskoy literatury. Moscow, AN SSSR Publ., vol. 12, pp. 105-115.

Luk A.N., 1982. Emotions and personality. Moscow, Znanie Publ. $176 \mathrm{p}$.

Rodionova S.E., 2004. Intensity and its place among other semantic categories. Slavyanskiy vestnik. Moscow, MAKS Press, iss. 2, pp. 300-313.

Rubinshteyn S.L., 1999. Fundamentals of General Psychology. Saint Petersburg, Piter Kom Publ. 720 p.

Theophanes the Recluse, 2004. Passion and struggle with them: Excerpts from creations and letters. Moscow, Danilovskiy blagovestnik Publ. 326 p.

Sheptukhina E.M., ed. 2015. Semantics of the old Russian verb: synchronic and diachronic aspects. Collective monograph. Moscow, Flinta; Nauka Publ., 352 p.

\section{SOURCES AND DICTIONARIES}

Life of St. Dimitry, Metropolitan of Rostov. RostovYaroslavskiy, Tipografiya A.Kh. Oppel, na Okruzhnoy ulitse Publ., 1902. 32 p.

Life in the holy fathers of our Mitrofan, in Schemonas of Makarios, the first bishop of Voronezh and the newly-born wonder-worker, and the Tale of finding and revealing his honest relics, and of the gracious signs and miraculous healings: Extracts from the acts and reports of the Holy Synod. Moscow, Sinod. tip. Publ., 1896. 74 p.

Georgievskiy V.T. Life and feats of St. Hilarion, Metropolitan of Suzdal ([um.] 1707 g.). Petrograd, M.D. Usov Publ., 1914. 28 p.

Life of St. Tikhon, Bishop of Voronezh, Zadonsky and All-Russia miracle worker. Odessa, Tip. i khromolit. E.I. Fesenko Publ., 1895. 36 p.

Dictionary of the Church Slavonic and Russian language, compiled by the Second Division of the Imperial Academy of Sciences. In 4 vols. Saint Petersburg, V Tipografii Imperatorskoy Akademii nauk, 1847. 
Е.Г. Дмитриева. Способы указания на интенсивность эмоционального переживания в житийных текстах

\section{Information about the Author}

Evgeniya G. Dmitrieva, Candidate of Sciences (Philology), Associate Professor, Department of Russian Philology, Volgograd State University, Prosp. Universitetsky, 100, 400062 Volgograd, Russia, eg_dmitrieva@volsu.ru, iryas@volsu.ru,https://orcid.org/0000-0001-5117-5677

\section{Информация об авторе}

Евгения Геннадьевна Дмитриева, кандидат филологических наук, доцент кафедры русской филологии, Волгоградский государственный университет, просп. Университетский, 100, 400062 г. Волгоград, Россия, eg_dmitrieva@volsu.ru, iryas@volsu.ru, https://orcid.org/0000-0001-5117-5677 